\title{
PENGARUH REKRUTMEN, DAN KOMITMEN ORGANISASI \\ TERHADAP KINERJA KEPALA SEKOLAH DASAR \\ KABUPATEN MANOKWARI
}

\author{
THE EFFECTS OF RECRUITMENT, AND ORGANIZATIONAL COMMITMENT ON \\ JOB PERFORMANCE OF \\ HEADMASTER OF ELEMENTARY SCHOOL \\ AT MANOKWARI REGENCY
}

\begin{abstract}
MINCE PARA'PAK*
Abstract:The aim of this research is to examine the effect of recruitment and organizational commitment on job performance. The research was conducted to all of headmaster at the city of Manokwari by using a survey method with path analysis applied in testing hypothesis. The number of 91 headmasters as sample was selected by using Slovin formula. The result of research indicates: (1) there is direct effect of recruitment on job performance, (2) there is direct effect of organizational commitment on job performance, (3) there is direct effect of on job performance.Based on those finding it could be concluded that any changing or variation wich occured to the job performance of headmasters atManokwari Regency had been effected by recruitment and organizational commitment.
\end{abstract}

Keywords: recruitment, organizational commitment, job performance.

\section{PENDAHULUAN}

Sekolah menempati posisi penting sebagai suatu institusi yang melaksanakan suatu proses pendidikan.Di lembaga inilah setiap anggota masyarakat dapat mengikuti proses pendidikan dengan tujuan mempersiapkan masyarakat dengan berbagai ilmu dan keterampilan agar lebih mampu berperan dalam kehidupan bermasyarakat. Sekolah mengemban fungsi posisi paling depan dalam melayani pendidikan masyarakat, sehingga sekolah harus memiliki berbagai standar yang sudah ditentukan oleh kementerian.

Sekolah sebagai suatu sistem yang memiliki komponen-komponen yang berkaitan satu sama lain untuk mencapai suatu tujuan yaitu peningkatan mutu pendidikan. Komponen tersebut diantaranya siswa, kurikulum, guru, kepala sekolah dan masyarakat. Semua komponen tersebut harus dikembangkan melalui delapan standar kompetensi pendidikan.

Kinerja kepala sekolah merupakan faktor yang signifikan dalam proses pencapaian tujuan-tujuan pendidikan sekolah, apabila kompetensi kepala sekolah baik maka kemajuan sekolah akan tercapai, demikian juga sebaliknya. Sebagai pemimpin, kepala sekolah dituntut untuk berupaya keras untuk mengelola seluruh kegiatan di sekolah secara efektif dan efisien, agar tujuan pendidkan seseuai dengan harapan.

Fungsi kepala sekolah adalah sebagai motivator dan top manajer di sekolah diharapkan dapat memainkan perannya dalam penyelenggaraan pendidikan disekolah. Sebagai seorang motivator kepala sekolah harus mampu membimbing semua komponen yang ada di sekolah dan memiliki komitmen yang tinggi terhadap

\footnotetext{
* Guru SMP Negeri Satap Wasegi Distrik Prafi Kabupaten Manokwari.
} 
bawahannya. Pengangkatan kepala sekolah yang tidak didasarkan pada rekrutmen yang tepat akan berdampak pada komitmen yang rendah, dan ini akan berpengaruh pada kinerja kepala sekolah. Faktor lain yang mempengaruhi kinerja kepala sekolah adanya pengawasan yang dilakukan oleh pengawas sekolah dengan melaksanakan supervise yang terencana dan berkelanjutan pengawas dapat melakukan pembinaan dan perbaikan pengembangan kompetensi kepala sekolah sehingga meningkatkan kinerja. Dari pengamatan penulis di lapangan pengawas tidak pernah datang ke sekolah untuk melaksanakan supervisi, sehingga berdampak pada kurangnya perhatian kepala sekolah terhadap sekolah yang berdampak pada komitmen yang rendah.

Kepala Dinas Pendidikan, Pemuda, dan Olahraga (Disdikpora) Kabupaten Manokwari, Bapak Barnabas dalam sambutannya pada penyambutan tahun baru 2015 menyampaikan bahwa hendaknya guru dan terutama kepala sekolah lebih meningkatkan kinerja. Hal tersebut dikarenakan kinerja yang diharapkan masih belum optimal. Oleh karena itu moment perayaan tahun baru 2015 dijadikan momentum untuk berbenah diri bagi para guru dan kepala sekolah melalui jargon tahun baru semangat baru.

Pernyataan di atas memberikan gambaran umum bahwa perlu adanya peningkatan kinerja guru terutama kepala sekolah. Untuk itu, perlu dilakukan berbagai langkah agar ekspektasi akan terjadinya peningkatan kinerja kepala sekolah secara siginifikan dapat terwujud.

\section{Kinerja}

Jason A. Colquitt, Jeffery A. LePine, and Michael J. Wesson (2011:35) mendefinisikan bahwa, "job performance is formally defined as they value of the set of employee behavior that contribute, either positively or negatively to organizational goal accomplishment". Kinerja secara formal didefinisikan sebagai seperangkat nilai perilaku yang memiliki konstribusi baik secara positif maupun negatif untuk mencapai tujuan organisasi.

Definisi tersebut mengaitkan hal yang berhubungan dengan perilaku atau sikap seseorang terhadap organisasi baik yang posistif maupun negatif dalam mencapai tujuan organisasi. Dengan demikian seseorang dapat berkinerja baik maka orang tersebut harus mempunyai perilaku yang positif. dalam melaksanakan tugas yang diembannya untuk mencapai tujuan organisasi tempat yang bersangkutan bekerja.

Menurut pendapat Steve M. Jex (2002:88) "job performance is a deceptively simple term, at the most general level. It can be defined simply as of the behavior employees engage in while at work". Berdasarkan konsep tersebut kinerja pada tataran umum mempunyai pengertian yang sederhana, yaitu sebagai perilaku karyawan di tempat kerja.

Kemudian kinerja menurut Schermerhorn (2010:368) berpendapat bahwa"job performance is measured as the quantity and quality of task accomplished by an individual or group". Kinerja diukur sebagai kuantitas dan kualitas tugas yang dicapai oleh individu atau kelompok.

Sementara itu, Steven McShane \& Van Glinow (2003:127),"individual's performance is influenced by motivation, ability, role perception and situational factors". Kinerja seseorang dipengaruhi oleh motivasi, kemampuan, persepsi terhadap aturan, dan situasi. Motivasi adalah proses representasi dorongan dari dalam individu yang mempengaruhi arah dan orientasi tujuan. Kemampuan adalah perpaduan antara potensi yang secara herediter dibawa seseorang sejak lahir berupa kemampuan khusus atau bakat, dan kemampuan mental dan fisik. Persepsi peran adalah keyakinan seseorang tentang perilaku apa yang tepat dan perlu dalam situasi khusus. Faktor 
situasional adalah lingkungan dan keadaan dimana seseorang berada yang dipengaruhi oleh waktu, fasilitas, rekan kerja, gaya manajemen serta sarana dan fasilitas yang mempengaruhi suasana dan hasil kerja seseorang.

Senada dengan hal tersebut, Lioyd (2011:214) mengatakan bahwa, "job performance is the net effect of an employee's effort as modified by abilities and role (or task) perception". Kinerja adalah efek bersih dari upaya pegawai yang dimodifikasi berdasarkan persepsi kemampuan dan peran (tugas).

Sedangkan Gibson et.al (2102:314) mendefinisikan kinerja dengan, "job performanceis such as quality, efficiency, and other criteria of effectiveness". Kinerja adalah hasil dari pekerjaan yang berhubungan dengan tujuan organisasi seperti kualitas, efisiensi, dan kriteria efektifitas lainnya. Kinerja yang baik adalah langkah menuju pencapaian tujuan organisasi. Agar diperoleh hasil kinerja yang tinggidalam sebuah organisasi termasuk di dalam sekolah maka diperlukan berbagai upaya seperti kemampuan manajemen seorang kepala sekolah. Sementara itu, Craig C. Pinder (2007:76) menyatakan bahwa "job performance is the accomplishment of work related goals, regardless of the means of their accomplishment". Kinerja adalah prestasi pencapaian tujuan kerja dengan keberhasilan prestasi mereka. Hasil yang maksimal dalam kinerja menunjukkan adanya tanggung jawab tinggi yang dimiliki oleh seseorang dalam melaksanakan dan menyelesaikan tugas sesuai dengan standar kualitas, kuantitas, dan batas waktu yang telah ditentukan.

Berdasarkan uraian di atas dapat disintesiskan bahwa kinerja adalah perilaku kerja seseorang dalam melaksanakan tugas dan tanggung jawab yang diembannya dengan indikator; (1) pelaksanaan tugas rutin, (2) efektivitas dalam bekerja, (3) kapasitas dalam bekerja, (4) kualitas pelaksanaan pekerjaan, (5) efisiensi pekerjaan.

\section{Komitmen Organisasi}

Gibson, Ivancevich dan Donnely (2102:182) menyatakan bahwa,"organizational commitmen is a sense of identification, loyalty involvement expressed by an employee toward the organization or unit of the organization."Komitmen organisasi merupakan suatu bentuk identifikasi, loyalitas, dan keterlibatan yang diekspresikan oleh karyawan terhadap organisasi atau unit. Dalam hal organisasi sekolah, kepala sekolah sebagai pemimpin dituntut mampu menunjukkan komitmen yang tinggi di dalam melaksanakan tugas dan tanggungjawabnya. Kepala sekolah yang memiliki komitmen yang tinggi senantiasa menunjukkan daya juang yang tinggi, tidak mudah menyerah ketika menghadapi berbagai masalah dan rintangan dalam melaksanakan tugas.

Jason A. Colquit dan Jeffery A. LePine (2011:68) mendefinisikan bahwa,organizational commitment is defined as the desire on the part of an employee to member of the organizational." Komitmen organisasi didefinisikan sebagai keinginan dari karyawan untuk tetap menjadi anggota organisasi. Karyawan yang tidak berkomitmen untuk organisasi mereka terlibat dalam pengunduran diri berupa sikap menghindari situasi kerja, perilaku ini dapat mengarah dan berujung pada pemberhentian diri dari organisasi.

Menurut Kreitner and Angelo (2006:221),"organizational commitment reflecs the extent to which an individual identifies withand is commetted to is goal." Memaknai komitmen organisasi dalam sebuah gambaran tentang bagaimana individu mengidentifikasi dirinya dengan organisasi dan kemudian terikat dengan tujuan-tujuan.

Fred Luthans (2008:127) mengemukakan bahwa as an attitude, organizational commitment is most often defined as: (1) a strong desire to remain a member of a particular organization, (2) a willingness to exert high levels of effort on behalf of the organization, and (3) 
a definite belief in, and acceptance of, the values and goals of organization."Komitmen organisasi sebagai : (1) keinginan kuat untuk tetap sebagai anggota organisasi,(2) keinginan untuk berusaha keras sesuai dengan keinginan organisasi dan (3) keyakinan tertentu dan penerimaan nilai dan tujuan organisasi. Dalam pengertian ini, komitmen organisasi dapat dikatakan sebagai sikap loyalitas karyawan terhadap organisasi yang merupakan proses yang berkesinambungan melalui organisasi tersebut maka karyawan akan menunjukkan kesetiaannya terhadap organisasi.

McShane dan Von Glinow (2003:127) menyatakan bahwa," organizational commitment refers to the employee's emotional attachment to, identification with, and involvement in a particular organization". Komitmen organisasi merupakan ikatan emosional karyawan yang diidentifikasikan dengan keterlibatan dalam organisasi. Hal ini memberikan makna bahwa komitmen afektif tertuju kepada keterikatan emosional dalam bentuk kekesetiaan kepada organisasi.

Demikian halnya dengan Griffin and Moorhead (2014:74) menyampaikan bahwa, "organizational commitment is a person's identification with and attachment to an organizational". Komitmen organisasi adalah identifikasi perasaan menyatu seseorang dengan dan terhadap organisasi.

Dari uraian di atas dapat disintesiskan bahwa komitmen organisasi adalah sikap loyalitas dan keterlibatan individu dalam keterikatan hubungan dengan organisasi yang ditandai dengan indikator; (1) perilakuyang positif terhadap organisasi, (2) keterlibatan dalam pekerjaan, (3) keinginan yang kuat untuk berusaha keras, (4) kesungguhan secara maksimal dalam menggunakan keterampilan, (5) kesediaan melakukan perubahan diri, (6) keinginan yang kuat untuk bertahan dalam organisasi.

\section{Rekrutmen}

Lynn Van der Wagen (2007:124) mendefinisikan bahwa," recruitment is the process of attracting potential candidates to the organization". Rekrutmen adalah proses menarik calon yang memiliki potensi bagi organisasi. Hal senada dikemukakan oleh Stephen Pilbeam dan Marjorie," recruitment is the a process which aims to attract appropriately candidates for a particular position from which it is possible and practical to select and appoint a competent person or persons." Rekrutmen adalah proses untuk menarik calon dengan kualifikasi yang sesuai untuk posisi tertentu yang mungkin dan praktis untuk memilih dan menunjuk seseorang atau beberapa orang yang kompeten. Ini berarti proses rekrutmen difokuskan pada kompetensi perilaku yang dimiliki oleh seseorang. Proses perekrutan menitikberatkan pada tiga hal: (1) Keterampilan dan pengetahuan harus secara khusus terkait .dengan kebutuhan pekerjaan;(2) Pendidikan dan pelatihan ; (3) Kriteria yang meliputi kualitas pribadi.

Menurut Shaun Tyson (2006:143)," recruitmentis the activity which produces candidates, which helps to establish the employer brand, and through recruitment policies has a major impact on the organizational culture". Rekrutmen adalah kegiatan yang menghasilkan calon, yang membantu untuk membangun merek majikan, dan melalui kebijakan perekrutan memiliki dampak besar pada budaya organisasi. Tujuan dari perekrutan adalah untuk menarik calon yang benar-benar cocok dan memiliki kemampuan untuk mengisi sebuah jabatan yang kosong. Perekrutan yang efisien dapat digambarkan untuk mengetahui sumber daya yang diinginkan, sumber daya yang tersedia, serta dimana dan bagaimana mereka menemukan biaya yang efektif. Persyaratan proses rekrutmen yang efisien dan sistematis serta memudahkan pemeriksaan maka difokuskan pada;(1) menentukan lowongan; (2) menentukan 
strategi; (3) kebijakan rekrutmen; (4) mempersiapkan dan mempublikasikan informasi; (5) pengolahan dan aplikasi menilai;(6) memberitahukan pelamar.

Sementara itu, Menurut Michael Armstrong (2009:515), "recruitment is the process of finding and engaging the people the organization needs". Rekrutmen adalah proses mencari dan menarik orang-orang yang dibutuhkan organisasi. Sistem rekrutmen yang berkualitas dan dilaksanakan secara konsisten, merupakan salah satu faktor yang menentukan dalam upaya peningkatan mutu sekolah.

Werther and Davis (2004:471) mengemukakan rekrutmen sebagai berikut "recruitment isaprocess through which an enterprise attracts individuals with suitable job knowledge and ability. Therefore, whether an enterprise can recruit high quality personnel depends on proper recruitment procedures."Rekrutmen merupakan proses dimana suatu perusahaan menarik individu untuk menentukan kemampuan yang cocok dengan kinerja. Oleh karena itu, apakah suatu perusahaan dapat mempekerjakan pegawai dengan kualitas tinggi tergantung pada prosedur perekrutan yang tepat.

De Cenzo dan Robbins (1994:409) menyatakan bahwa, "claimed that the recruitment procedure includes initialinterview screening, completing the application form, general interview, background check, job offer, physical check, and permanent employment". Prosedur perekrutan meliputi screening wawancara awal, mengisi formulir aplikasi, wawancara umum, latar belakang, pemeriksaan fisik, agar konsisten dengan kinerja yang dinginkan. Werther dan Davis mengklasifikasikan metode perekrutan yang digunakan oleh desainer industri menjadi tes tertulis, wawancara, dan desain proyek.

Beberapa penyataan di atas dapat disintesiskan bahwa rekrutmen adalah proses untuk menarik seseorang yang memiliki kualifikasi yang sesuai, kompetensi, keterampilan (keahlian), dan pengetahuan sesuai dengan bidangnya yang dilakukan oleh pimpinan dengan indikator:(1) kesesuaian potensi, (2) kesesuaian kemampuan (3) kesesuaian kualifikasi, dan (4) kesesuaian kebutuhan.

\section{HASIL DAN PEMBAHASAN}

\section{Pengaruh Rekrutmen $\left(X_{1}\right)$ terhadap Kinerja $\left(X_{3}\right)$}

Dari hasil perhitungan analisis jalur, pengaruh langsung rekrutmen terhadap kinerja Kepala SD Kabupaten Manokwari diperoleh nilai koefisien korelasi sebesar 0,442 dan nilai koefisien jalur sebesar 0,339 . Dengan demikian, mewujudkan rekrutmen yang baik maka kepala sekolah memiliki pencapaian kinerja yang tinggi. Jason A. Colquitt, Jeffery A. LePine, and Michael J. Wesson (2011:35) mendefinisikan bahwa, "job performance is formally defined as they value of the set of employee behavior that contribute, either positively or negatively to organizational goal accomplishment". Kinerja secara formal didefinisikan sebagai seperangkat nilai perilaku yang memiliki konstribusi baik secara positif maupun negatif untuk mencapai tujuan organisasi. Menurut Michael Armstrong (2009:515), "recruitment is the process of finding and engaging the people the organization needs". Rekrutmen adalah proses mencari dan menarik orang-orang yang dibutuhkan organisasi. Sistem rekrutmen yang berkualitas dan dilaksanakan secara konsisten, merupakan salah satu faktor yang menentukan dalam upaya peningkatan mutu.

Hal ini sejalan dengan teori James A. Breaugh (2009:28) mengatakan bahwa "effective recruiting will improve your applicant pool, the quality of the people you hire and even the job performance and retention of these new employees". Rekrutmen yang efektif akan meningkatkan pelamar, kualitas pekerja yang dikontrak, dan bahkan kinerja dan retensi karyawan baru. 
Mustapha, Ilesanmi,danAremu (2013:1) dalam penelitiannya mengemukakan bahwa: The Impact of Well Planned Recruitment and Selection Process on Corporate Performance in Nigerian Banking Industry" memaparkan bahwa, "effective recruitment and selection is a key to organizational commitment; that a well planned recruitment and selection impact, to organizational performance". Rekrutmen dan seleksi yang efektif adalah kunci utama komitmen organisasi; perencanaan rekrutmen yang baik berdampak terhadap kinerja organisasi. Demikian halnya di sekolah, kepala sekolah yang memiliki kompetensi akan mampu memainkan perannya sebagai seorang manajer, maka perlu diangkat melalui rekrutmen yang jelas. Pengangkatan kepala sekolah yang didasarkan pada proses yang baik dapat mewujudkan ekspektasi berbagai pihak terutama masyarakat kepala sekolah memiliki komitmen yang tinggi yang pada akhirnya akan meningktakan kinerja yang lebih baik. Begitupun dengan pendapat John $\mathrm{R}$. Schemerhorn (2010:303) yang mengatakan bahwa "a history of serious internal recruitment also builds employee loyalty and motivation, showing that one can advance by working hard and doing well when given responsibility". Dalam perjalanan sejarah rekrutmen internal yang serius juga membangun loyalitas dan motivasi, menunjukkan kemajuan berupa bekerja keras dan melakukan pekerjaan dengan baik saat mendapatkan tanggung jawab. Bekerja keras dan melakukan pekerjaan dengan baik merupakan indikator utama dalam kinerja. Jadi, rekrutmen internal dapat juga membangun kinerja.Berdasarkan uraian di atas, dapat diduga terdapat pengaruh rekrutmen terhadap kinerja. Jika rekrutmen jelas,maka kinerja sesorang akan meningkat.

\section{Pengaruh Komitmen Organisasi $\left(X_{2}\right)$ terhadap KInerja $\left(X_{3}\right)$}

Dari hasil perhitungan analisis jalur, pengaruh langsung komitmen organisasi terhadap kinerja. Kepala SD Kabupaten Manokwari diperoleh nilai koefisien korelasi sebesar 0,432. Dan nilai koefisien jalur sebesar 0,324. Dengan demikian, meningkatkan kinerja kepala sekolah dapat dilakukan dengan meningkatkan komitmen organisasi. Gibson, Ivancevich dan Donnely (2102:182) menyatakan bahwa,"organizational commitmen is a sense of identification, loyalty involvement expressed by an employee toward the organization or unit of the organization."Komitmen organisasi merupakan suatu bentuk identifikasi, loyalitas, dan keterlibatan yang diekspresikan oleh karyawan terhadap organisasi atau unit.

Hal ini sesuai dengan yang diungkapkan Michael Amstrong (2007:336) yang mengatakan bahwa "employee engagement and organizational commitment are two important concepts affecting work performance and the attraction and retention of employees". Keterlibatan karyawan dan komitmen organisasi adalah dua konsep penting yang mempengaruhi kinerja dan daya tarik dan retensi karyawan.

Hal ini juga senada dengan pendapat Meye dan Alien (2010:296) memaparkan bahwa, "in the previous studies of the concept commitment have substantiated that employee commitment to the organisation has a positive influence on job performance". Dalam penelitian sebelumnya tentang konsep komitmen telah dibuktikan bahwa komitmen karyawan terhadap organisasi memiliki pengaruh positif terhadap kinerja. Kepala sekolah yang memilki komitmen yang tingi akan menunjukkan kinerja yang tinggi.

Begitupun Elangovan (2013:165) mengutarakan bahwa, "commitment of employees can be an important instrument for improving the performance of the organizations". Komitmen pegawai dapat menjadi instrumen dalam meningkatkan kinerja.Dalam hal organisasi 
sekolah, kepala sekolah sebagai pemimpin dituntut mampu menunjukkan komitmen yang tinggi di dalam melaksanakan tugas dan tanggungjawabnya. Kepala sekolah yang memiliki komitmen yang tinggi senantiasa menunjukkan daya juang yang tinggi, tidak mudah menyerah ketika menghadapi berbagai masalah dan rintangan dalam melaksanakan tugas.Dari uraian di atas dapat diduga bahwa terdapat pengaruh komitmen organisasi terhadap kinerja.

\section{Pengaruh Rekrutmen $\left(X_{1}\right)$ terhadap Komitmen Organisasi $\left(X_{2}\right)$}

Dari hasil perhitungan analisis jalur, pengaruh langsung rekrutmen terhadap komitmen organisasi Kepala SD Kabupaten Manokwari diperoleh nilai koefisien korelasi sebesar 0,318 dan nilai koefisien jalur sebesar 0,318. Dengan demikian, terwujudnya rekrutmen yang baik akan berpengaruh langsung terhadap peningkatan komitmen organisasi. Michael Armstrong (2009:515) menjelaskan, "recruitment is the process of finding and engaging the people the organization needs". Rekrutmen adalah proses mencari dan menarik orang-orang yang dibutuhkan organisasi. Lynn Van der Wagen (2007:124) mendefinisikan," recruitment is the process of attracting potential candidates to the organization". Rekrutmen adalah proses menarik calon yang memiliki potensi bagi organisasi. Hal ini senada dengan pendapat Richard L. Daft (2010:318) yang mengatakan bahwa "internal recruiting has two major advantages: it less costly than an external search, and it generates higher employee commitment". Rekrutmen internal memiliki dua keuntungan utama, yaitu minimnya biaya dibandingkan dengan eksternal, dan menghasilkan komitmen pegawai yang lebih tinggi.

Begitupun Fred Luthans (2002:236) menggambarkan rekrutmen dan komitmen organisasi bahwa "organizational commitment of employees can also be increased by recruitment committing the values of people first by giving them proper compensation, promotion, training, fringe benefits etc". Komitmen organisasi karyawan juga dapat ditingkatkan dengan melakukan perekrutan dengan nilai-nilai yang memberikan kompensasi yang layak, promosi, pelatihan,dan tunjangan. Tahap rekrutmen sebagai periode ketika sebuah perusahaan menggunakan berbagai praktik yang berbeda untuk menarik individu yang berpedoman pada komitmen organisasi. Rekrutmen merupakan suatu proses untuk menarik seseorang yang memiliki kualifikasi yang sesuai kompetensi,keterampilan, dan pengetahuan sesuai dengan bidangnya. Rekrutmen yang tepat akan meningkatkan komitmen yang tinggi, yang dimiliki kepala sekolah sehingga berpengaruh terhadap kinerja. Dari uraian di atas dapat diduga terdapat pengaruh rekrutmen terhadap komitmen organisasi.

\section{PENUTUP}

Kesimpulan: Berdasarkan hasil analisis data dan perhitungan statistik sebagaimana yang telah diuraikan sebelumnya maka temuan dari hasil penelitian ini dapat disimpulkan bahwa (1) rekrutmen berpengaruh langsung positif terhadap kinerja. Artinya ketepatan dalam rekrutmen menyebabkan peningkatan kinerja Kepala SD di Kabupaten Manokwari. (2) komitmen organisasi berpengaruh langsung positif terhadap kinerja. Artinya peningkatan komitmen organisasi menyebabkan peningkatan kinerja 
Kepala SD di Kabupaten Manokwari. (3) rekrutmen berpengaruh langsung positif terhadap komitmen organisasi. Artinya ketepatan dalam rekrutmen menyebabkan peningkatan komitmen organisasi Kepala SD di Kabupaten Manokwari.

Saran: Beberapa saran terkait dengan penelitian ini mencakup sebagai berikut: (1) Kepala Dinas Pendidikan, Pemuda, dan Olahraga Kabupaten Manokwari selaku pengambil kebijakan tertinggi di satuan pendidikan tingkat kabupaten/kota perlu memperhatikan berbagai variabel berkenaan dengan upaya peningkatan kinerja kepala sekolah. Rekrutmen dan komitmen organisasi merupakan variabel yang sangat disarankan untuk diperhatikan dan diterapkan agar kinerja kepala sekolah senantiasa meingkat sesuai dengan harapan. (2) Pihak Kepala Dinas Pendidikan, Pemuda, dan Olahraga Kabupaten Manokwari agar senantiasa mewujudkan proses rekrutmen yang baik pada pemilihan kepala sekolah agar senantiasa dapat berimplikasi positif pada kinerja kepala sekolah yang lebih tinggi sehingga dalam melaksanakan tugas kesehariannya yang merupakan tanggung jawabnya dapat terwujud.

\section{DAFTAR PUSTAKA}

Armstrong, Michael Armstrong's Handbook Of Human Resource Management Practice. USA: Kogan Page London and Philadelphia. 2009.

Breaugh, James A. Recriuiting and Atractive Talent: A Guide to Understanding and Managing The Process Recruitment. Alexandria: SHRM Foundation. 2009.

Byars, Lioyd L. Human Resources Management. New York: McGraw-Hill. 2011.

Colquitt, Le Pine, and Wesson, Organizational behavior: Improving Performance and Commitment in the work Place. New York: McGraw-Hill Companies. Inc. 2011.

DeCenzo, D.A. and Robbins, S.P. Human Resource Management: Concepts and Practices. New York: John Wiley \& Sons. 1994.

Goerge, Jennifer M dan Gareth J. Jones. Understanding and Managing Organizational Behavior. New Jersey: Pearson Education Inc.. 2012.

Gibson, Donelly, Ivancevich, dan Robert Konopaske. Organizations Behavior, Structure, Processes. New York: McGraw-Hill. 2012.

Griffin, Ricky W. Gregory Moorhead, Organizational Behavior: Managing People and Organizations, Eleventh Edition. South-Western, Cengange Learning. 2014.

Jex, Steve M. Organizational Psychology. New York: John Weley \& Sons. 2002.

Kreitner, Robert dan Angelo Kinicki, Oragnizational Behavior.New York: MCGraw-Hill Irwin. 2006. 
Luthan, Fred Orgaizational Behavior. New York: McGraw-Hill, 2008.

Lynn Van der Wagen. Human Resource Management For Events. USA: Elsevier, Ltd,2007.

McShane, Steven dan Von Glinow. Organizational Behavior. New York: Mc Graw-Hill. 2003.

Pinder, Craig C. Work Motivation in Organizational Behavior. New York: Pshychology Press. 2008.

Robbins, Stephen dan Timothy Judge. Organizational Behavior. New Jersey: Peerson Education Inc.. 2013.

Schemerhorn, et.al. Organizational Behavior. New Jersey: John Willey and Sons Inc.. 2010.

Werther, W.B. and Davis, K.J. Human Resources and Personnel management. 6th ed. New York: McGraw-Hill. 2003. 